\title{
Measurement of the Anisotropy Coefficient Development in Dependence on Deformation
}

Jiri Sobotka, Josef Bradáč

SKODA AUTO Vysoká škola o.p.s., Department of Logistics and Automotive Technology. Na Karmeli 1457, 29101 Mladá Boleslav, Czech Republic.E-mail: jiri.sobotka@savs.cz,josef.bradac@savs.cz

There are a lot of basic material characteristics that can generally describe the behavior of material. Among them, anisotropy coefficient ra [1] represents a very important material parameter - especially in the area of metal forming. Acc. to standard is such quantity determined as width and thickness strain values under the given magnitude of deformation. It means that anisotropy coefficient $r \alpha$ is always determined at one point (magnitude of deformation). In this paper was applied the contact-less optical system ARAMIS to determine values of ro through the whole static tensile test - more precisely from yield strength up to uniform ductility. Thus as a result there are curves of anisotropy coefficient vs. engineering strain for 3 rolling directions $\left(0^{\circ}, 45^{\circ}\right.$ and $\left.90^{\circ}\right)$ and their values are in the given points compared to the "standard" ones (conventional approach).

Keywords: Anisotropy Coefficient, Strain, Contact-less Measurement, Rolling Direction, Static Tensile Test

\section{Introduction}

Term anisotropy (or isotropy) represents a very important material characteristic. Generally, it means that properties of material are directionally dependent (properties are direction dependent). Due to the crystallographic structure (preferred orientation of grains) and the characteristics of the mechanical working of metals (e.g. by the rolling process), sheet metals generally exhibit a significant anisotropy of mechanical properties $[1,2,3]$.
E.g. slip on some slip planes can cause contraction in the plane of the sheet, but no thinning and that is why a useful parameter to quantify amount of plastic strain anisotropy was needed $[4,5]$. This parameter is termed as anisotropy coefficient $r_{\alpha}$ [1] and generally is computed acc. to equation (2). The major aim of this paper was to compare two different methods how to determine $r_{\alpha}$ by using material having specific deformation behavior (creation of socalled Lüders bands) - aluminium alloy AW-5182. Its basic mechanical properties are given in Tab. 1 and stressstrain curve is shown in Fig. 1.

Tab. 1 Basic mechanical properties of tested aluminium alloy $A W-5182$

\begin{tabular}{|c|c|c|c|c|}
\hline Alluminium alloy AW-5182 & \multicolumn{2}{|c|}{ Strength properties } & \multicolumn{2}{c|}{ Formability properties } \\
\hline Basic mechanical properties & $\begin{array}{c}\text { Proof yield } \\
\text { strenght } \\
\mathrm{R}_{\mathrm{p} 0.2}[\mathrm{MPa}]\end{array}$ & $\begin{array}{c}\text { Ultimate } \\
\text { strength } \\
\mathrm{R}_{\mathrm{m}}[\mathrm{MPa}]\end{array}$ & $\begin{array}{c}\text { Uniform } \\
\text { ducility } \\
\mathrm{A}_{\mathrm{g}}[1]\end{array}$ & $\begin{array}{c}\text { Total } \\
\text { ductility } \\
\mathrm{A}_{80 \mathrm{~mm}}[1]\end{array}$ \\
\hline Rolling direction $0^{\circ}$ & $\mathbf{1 5 3 . 5}$ & $\mathbf{2 9 5 . 5}$ & $\mathbf{2 2 . 2 4}$ & $\mathbf{2 3 . 4 1}$ \\
\hline Rolling direction $45^{\circ}$ & $\mathbf{1 4 9 . 3}$ & $\mathbf{2 8 9 . 6}$ & $\mathbf{2 3 . 7 1}$ & $\mathbf{2 3 . 8 7}$ \\
\hline Rolling direction $90^{\circ}$ & $\mathbf{1 5 4 . 8}$ & $\mathbf{2 9 4 . 1}$ & $\mathbf{2 1 . 5 8}$ & $\mathbf{2 2 . 7 8}$ \\
\hline
\end{tabular}

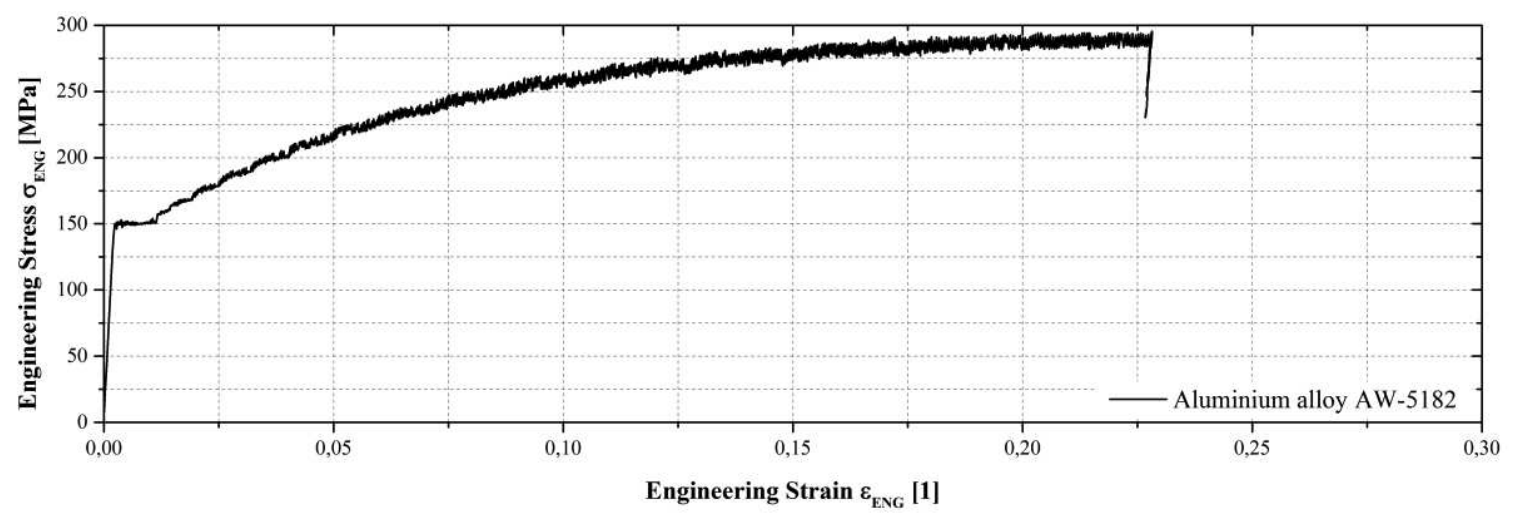

Fig. 1 Alluminium alloy AW-5182 - engineering stress-strain curve (rolling direction $0^{\circ}$ ) 


\section{Anisotropy coefficient $\mathbf{r}_{\alpha}-$ conventional meas- urement}

Conventional measurement of the anisotropy coefficient just follows the different orientation within the sheet where major rolling direction (RD) is taken as $0^{\circ}-$ see Fig. (2). It is quite simple measurement, which has just one big disadvantage - it is performed for one strain value only (given by standard). Thus as a result there is just one value for one deformation. Generally, the anisotropy coefficient $r_{\alpha}$ (also known as Lankford parameter) is defined as:

$$
r_{\alpha}=\frac{\epsilon_{T(w)}}{\epsilon_{T(t)}}
$$

$r_{\alpha}=\frac{\epsilon_{T(w)}}{\epsilon_{T(t)}}=\frac{\ln \left(\frac{w}{w_{0}}\right)}{\ln \left(\frac{t}{t_{0}}\right)}=\frac{\ln \left(\frac{w}{w_{0}}\right)}{-\ln \left(\frac{L w}{L_{0} w_{0}}\right)}=\frac{\ln \left(\frac{w_{0}}{w}\right)}{\ln \left(\frac{L w}{L_{0} w_{0}}\right)}$

where: $\varepsilon_{\mathrm{T}(\mathrm{L})}$ - true strain in the length direction [1], $\mathrm{w}_{0}, \mathrm{w}$ - initial and final width $[\mathrm{mm}]$,

$\mathrm{t}_{0}, \mathrm{t}$ - initial and final thickness $[\mathrm{mm}]$,

$\mathrm{L}_{0}$, L- initial and final length $[\mathrm{mm}]$.

Regarding the mechanical properties (mainly the uniform and total ductility values) of the tested aluminium alloy AW 5182, for conventional measurement was used engineering strain $\varepsilon_{\mathrm{ENG}}=0.140$ as deformation value. Width (both initial and final one) was computed as a mean of three values - thus there were measured three widths. Length (both initial and final one) was measured by means of high accuracy device - Abbe's comparator. Final results measured by the conventional measurement of anisotropy coefficient were as following:

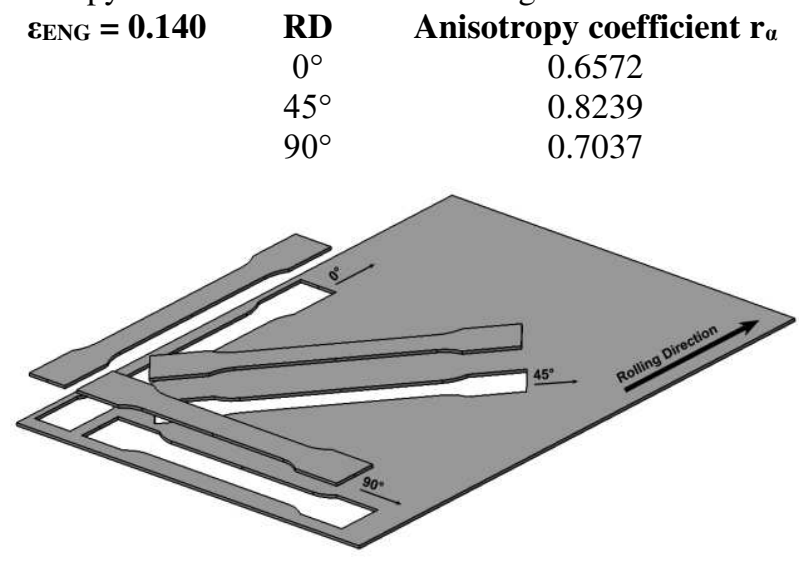

Fig. 2 Anisotropy coefficient with respect to the rolling direction (RD) of sheet

\section{Anisotropy coefficient $\mathbf{r}_{\alpha}-$ contact-less optical measurement (system ARAMIS)}

Contact-less optical measurement of the anisotropy coefficient was done by the optical system ARAMIS. It is a common optical device for contact-less deformation measurement. Generally, all these optical devices are based upon the photogrammetry (measurements from where: $\mathrm{r}_{\alpha^{-}}$anisotropy coefficient [1],

$\varepsilon_{\mathrm{T}(\mathrm{w})}$ - true strain in the width direction [1],

$\varepsilon_{\mathrm{T}(\mathrm{t})}$ - true strain in the thickness direction [1],

$\alpha$ - rolling direction within the sheet $\left[^{\circ}\right]$.

It is always quite very difficult to measure change of thickness in the equation (1) with high accuracy. And that is why this equation is a little bit modified by using the constant volume law in such manner that in the final equation for computation anisotropy coefficient are used only changes of width (more precisely widths) and length of sample. Such derivation of final equation (2) can be done as following:

$$
(t)=0 \rightarrow \epsilon_{T(t)}=-\left(\epsilon_{T(L)}+\epsilon_{T(w)}\right)
$$

photos - images) and that is why as a crucial element for the effective measurements there is preparation of sample and device itself. Thus firstly there was necessary to adjust proper shutter time, focus and carry out the calibration via so-called calibration panel (see Fig. 3).
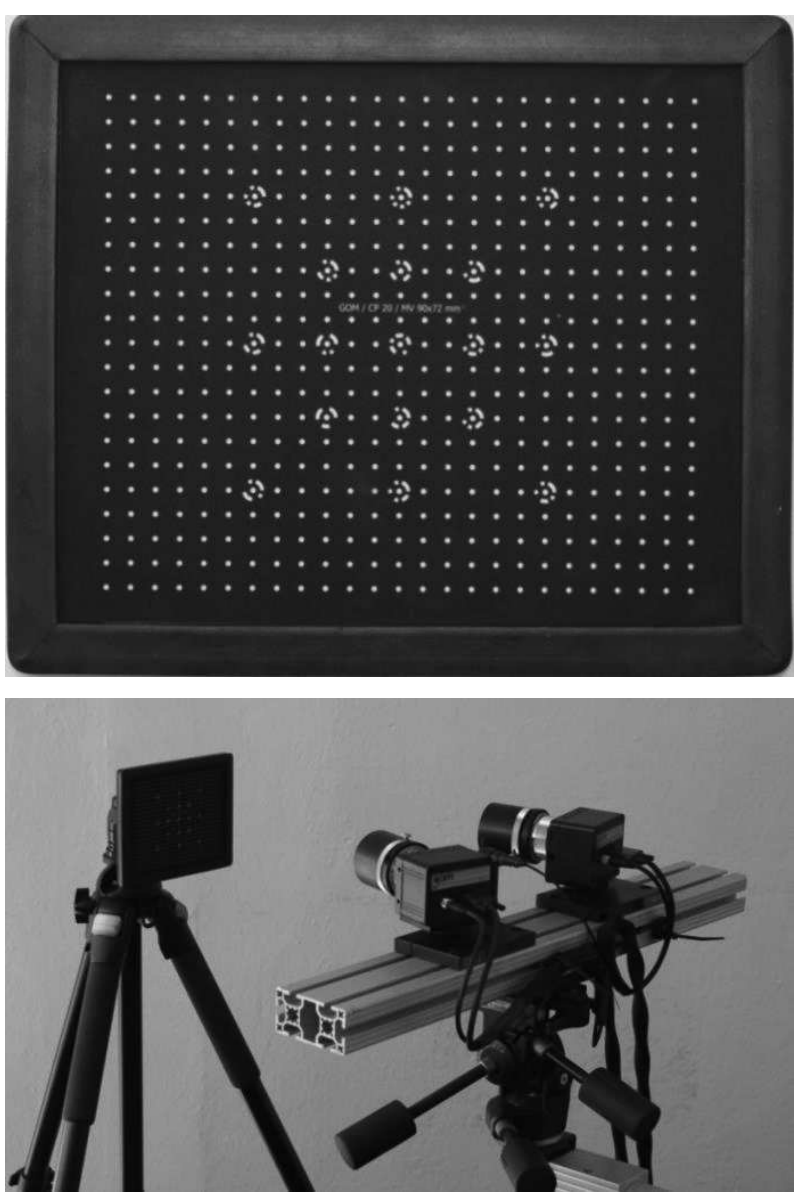

Fig. 3 Calibration panel (GOM MV $90 \times 72 \mathrm{~mm}^{2}$ ) to carry out calibration of the cameras

After calibration and preparation of testing samples (via application the stochastic pattern by means of spraying white background and small black dots), the optical system ARAMIS was ready to measure. TIRAtest 2300 was used as a testing device to carry out required tensile elongation of testing sample. Data scanning frequency 
was set to $6 \mathrm{fps}$. Final arrangement of the whole testing workplace is subsequently shown in Fig. 4 (1- scanning cameras, 2 - lighting device, 3 - PC for data evaluation, 4 - trigger box, 5 - TIRAtest 2300).

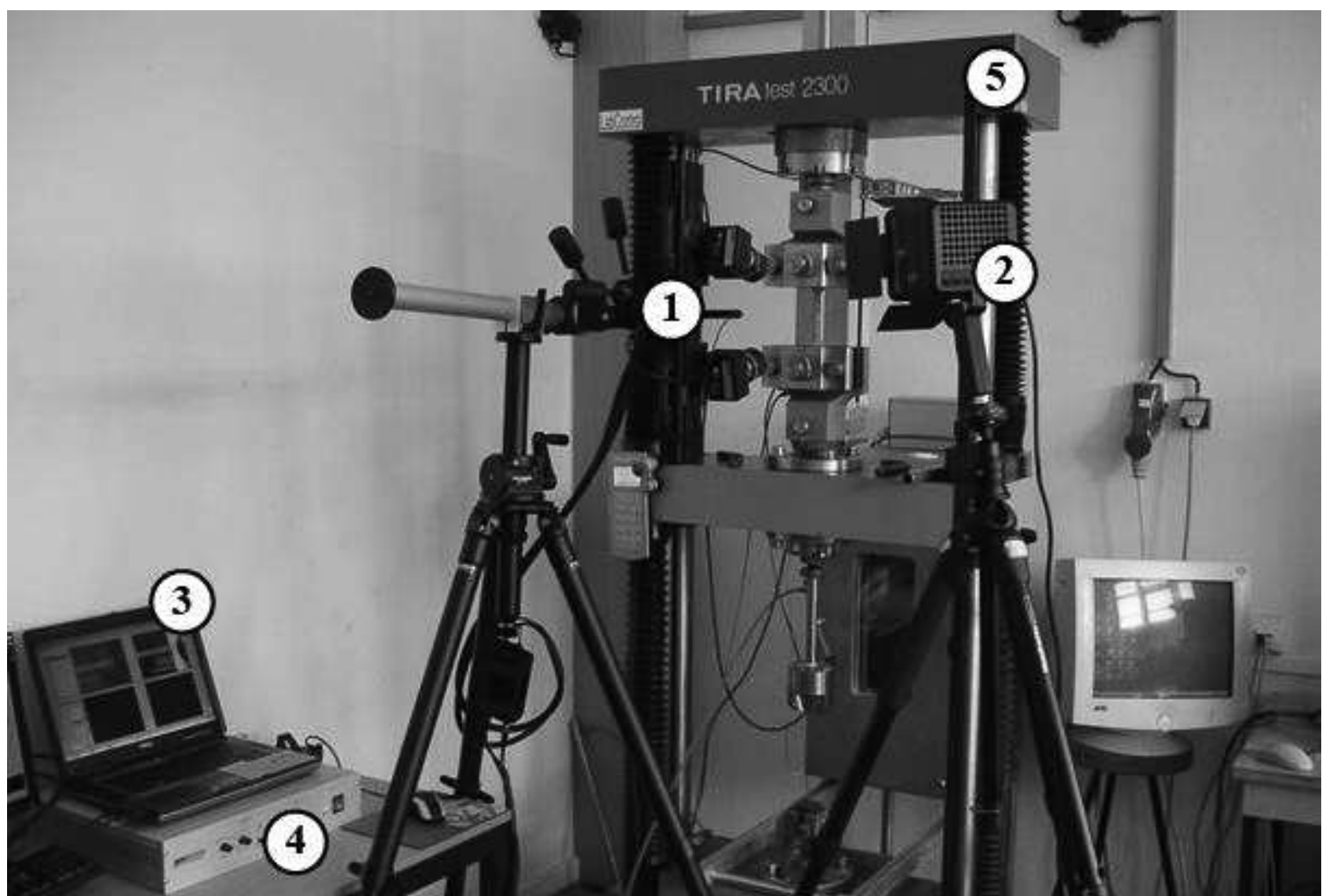

Fig. 4 Testing workplace for the contact-less optical deformation measurement

Own measurement was subsequently performed by means of so-called facets [px], where optical system just recognized their position in the calibration volume. Whole detected surface (via overlapping of facets) was finally taken as measured one. Fig. 5 (left) shows the testing sample with rolling direction $0^{\circ}$ not only as stage 0 (it measn undeformed stage - so engineering strain distribution equals zero) but mainly with the applied optical length gauges. There is Length 1 (initial length $\mathrm{L}_{0}$ $=80.235 \mathrm{~mm}$ ) and Width 1, 2 and 3. Fig. 5 (right) gives overview about changes within these measured widths. Already from shape of such data (stair-type), there is obvious creation of Lüders bands.

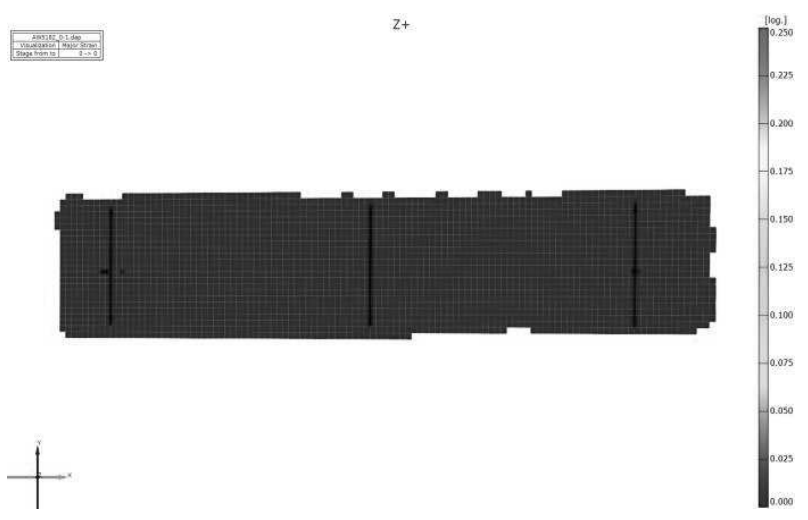

a)

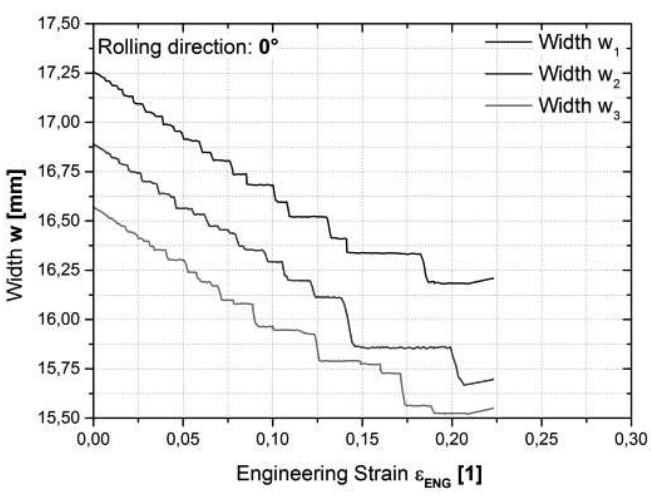

b)

Fig. 5 Undeformed stage with applied optical length gauges (a) and change of widths vs. engineering strain

(b)

Fig 6 gives a basic overview about the engineering strain distribution on the surface of tested sample (in this case for rolling direction $0^{\circ}$ and $\left.\varepsilon_{\mathrm{ENG}}=0.162\right)$. There is obvious creation of Lüders bands (slip bands), which is typical deformation behavior of tested aluminium alloy AW 5182 and also makes final measured curves rough. In Fig. 6 can be again observed used length (Length 1) and widths (Width 1, 2 and 3) measurement and also relevant magnitudes of these data. There are always 
written the initial values (nominal ones) as well as actual values and differences. These data were subsequently used to compute the anisotropy coefficient $r_{\alpha}$ by equation
(2). Contact-less optical measurement was for every tested sample performed up to fracture of sample, but necking area was always neglected (see page 5).
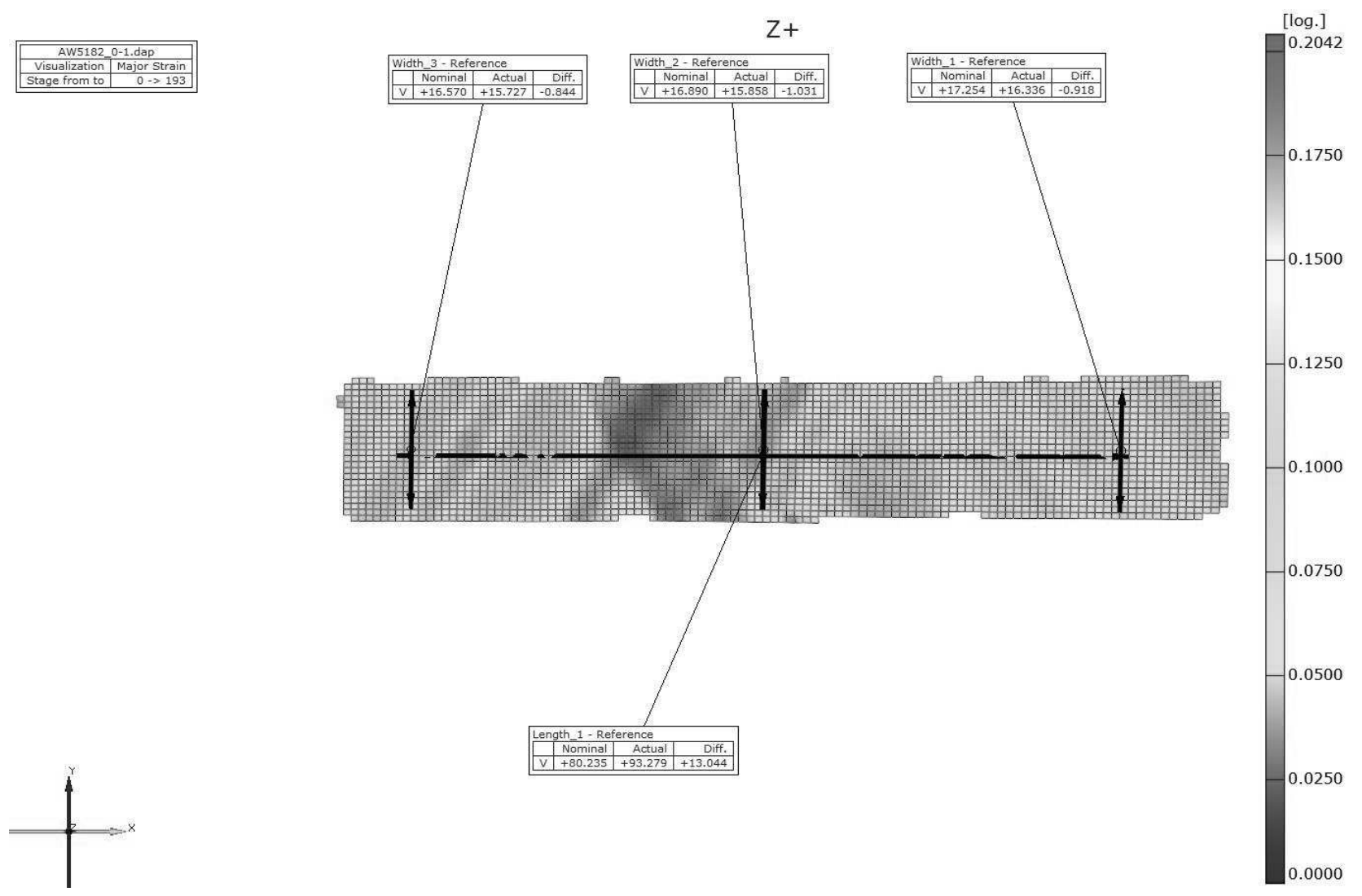

Fig. 6 Engineering strain distribution on the surface of tested sample $\left(R D 0^{\circ}, \varepsilon_{E N G}=0.162\right)$

\section{Comparison of the final results}

The determination of all necessary input data to compute the anisotropy coefficient $r_{\alpha}$ [1] by the contactless optical system ARAMIS was described on the previous page. Subsequently, there was used again equation (2) - in this case not only for one value of engineering strain but for the whole range on $\mathrm{X}$-axis (up to fracture of sample). Such graphical result is shown in Fig. 7 (left). However, there was necessary to "cut-off" the necking area - see Fig. 7 (right). In light of curve smoothness there wasn't used any smoothing technique because such shape was given by the own material deformation behavior and not by any inaccuracy occurred during the measurement.

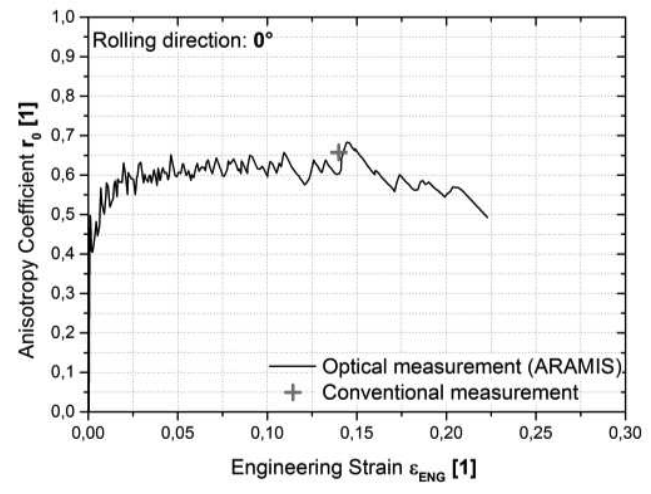

a)

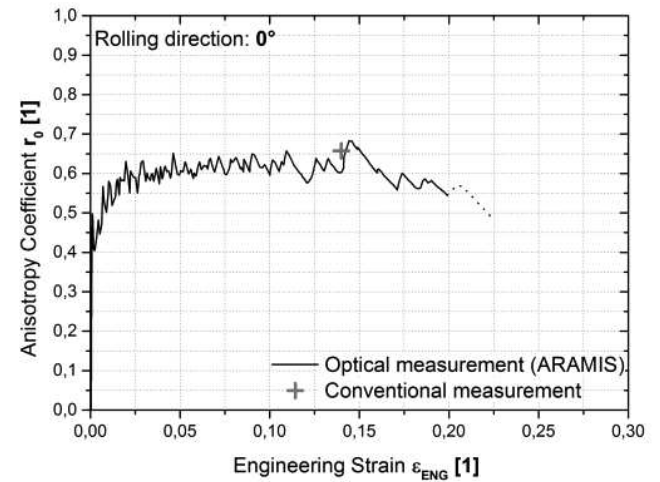

b)

Fig. 7 Whole measured curve anisotropy coefficient vs. engineering strain (a) and "cut-off" of necking area (b)

The major result is graphically shown in Fig. 8 (anisotropy coefficient vs. engineering strain). Both used measuring methods are shown there - from the conventional measurement there is just one point (red cross) at $\varepsilon_{\mathrm{ENG}}=0.140$ and form the contact-less optical measurement there is curve covering the full $\mathrm{X}$-axis (whole evolution). The exact comparison for one point on $\mathrm{X}$-axis $\left(\varepsilon_{\mathrm{ENG}}=0.140\right)$ is done on the following page. However, already from this graphical result there are obvious two major conclusions. The $1^{\text {st }}$ one is about the own difference that is quite small between the used 
methods and the $2^{\text {nd }}$ one deals with the shape of measured curve that is strongly influenced by the deformation behaviour of tested aluminium alloy AW 5182 - creation of slip bands which always influences the width in this region.

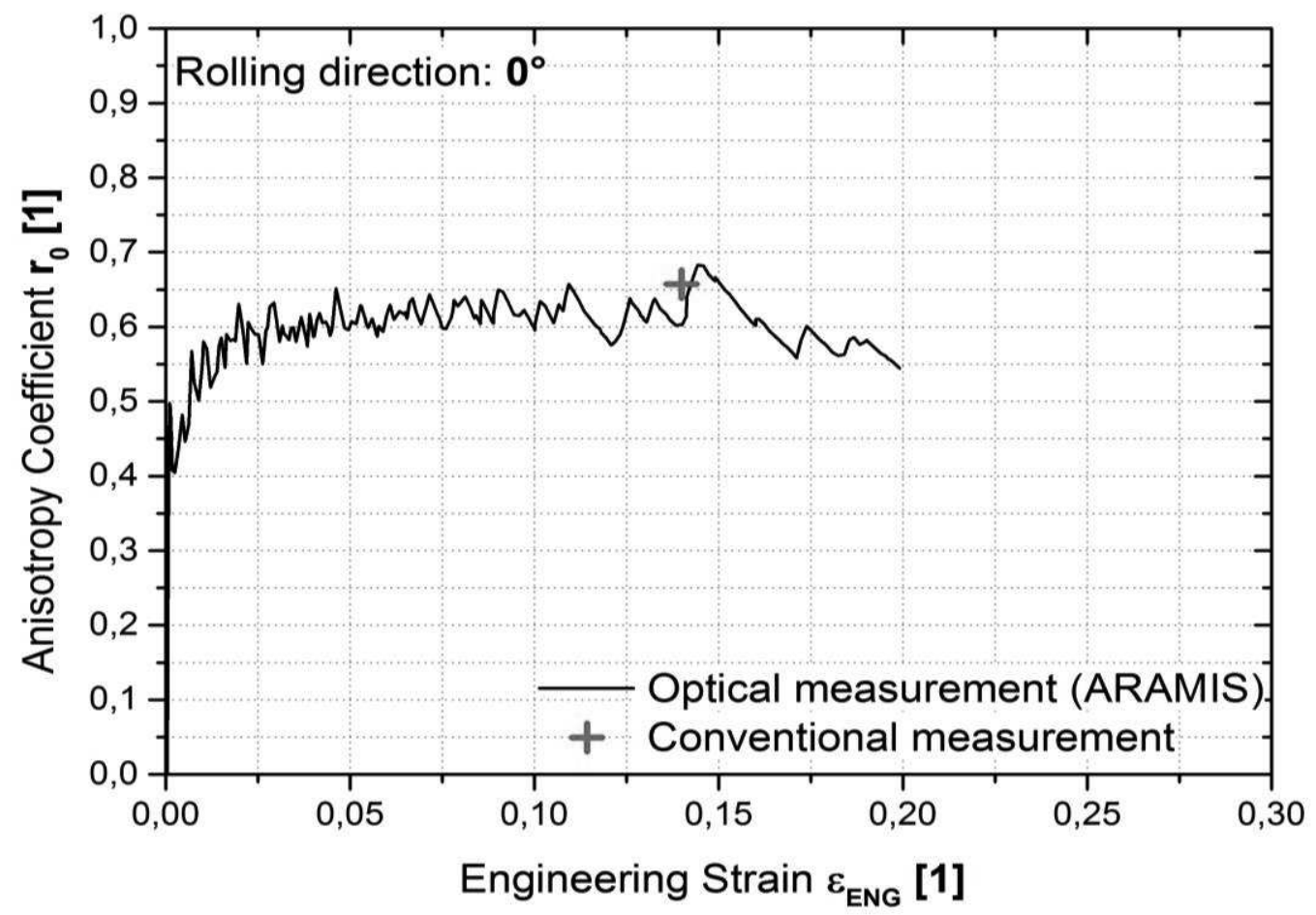

Fig. 8 Final graphical result comparing the conventional and optical measurement of anisotropy coefficient

In Fig. 9 and Fig. 10 are subsequently shown these graphical results for the other tested rolling directions thus for $45^{\circ}$ and $90^{\circ}$, regarding the rolling direction. As it was already possible to observe from the contact-less optical measurement, there is obvious very strong influence of the tested aluminium alloy AW 5182 deformation behavior (creation of Lüders bands) on the smoothness of final measured curves.

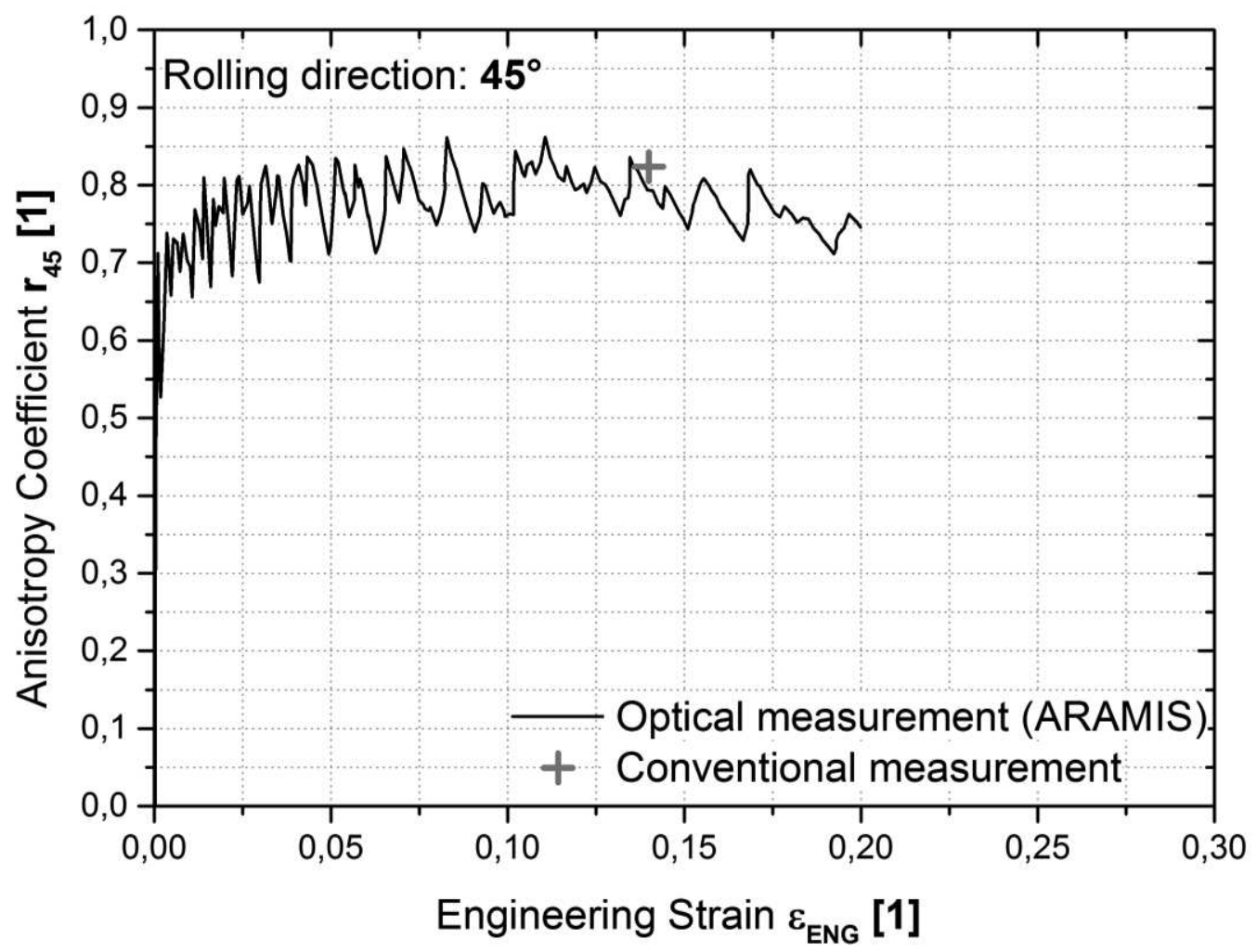

Fig. 9 Comparing of conventional and optical measurement for rolling direction $45^{\circ}$ 


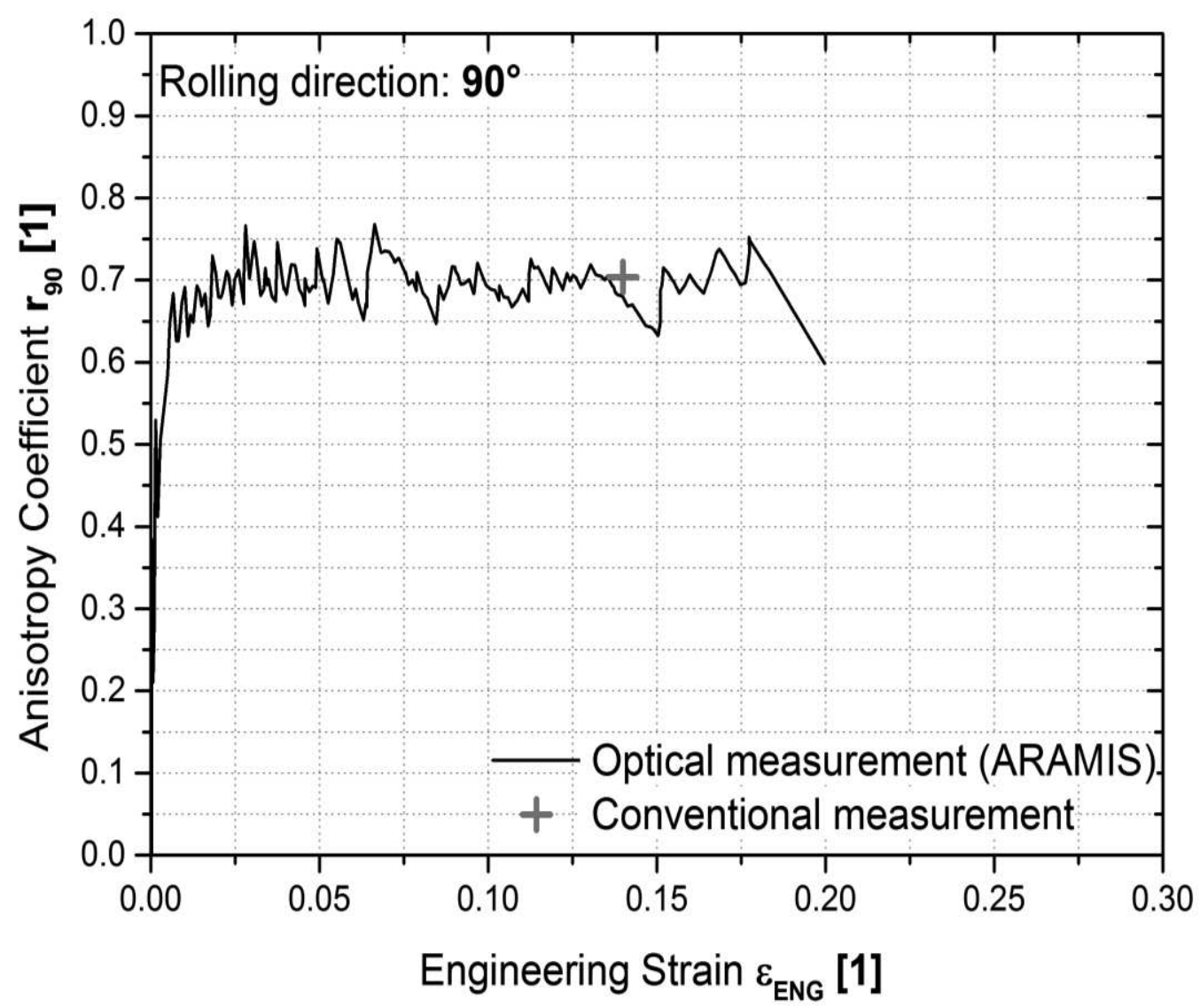

Fig. 10 Comparing of conventional and optical measurement for rolling direction $90^{\circ}$

Nevertheless, as the major aim of this paper there was comparison of the anisotropy coefficient values measured by two different methods at engineering strain $\varepsilon_{\mathrm{ENG}}=$
0,140 . As $100 \%$ there were taken values from the conventional measurement and graphically are these data shown in Fig. 11 with basic data overview above.

$\begin{array}{ccccc}\text { EENG }=\text { 0.140 } & \text { RD } & \text { Convectional measurement } & \text { Optical measurement } & \text { Difference [\%] } \\ & 0^{\circ} & 0.6572 & 0.6030 & \mathbf{- 8 . 2 4 \%} \\ & 45^{\circ} & 0.8239 & 0.7939 & \mathbf{- 3 . 6 4 \%} \\ & 90^{\circ} & 0.7037 & 0.6807 & \mathbf{- 3 . 2 6 \%}\end{array}$

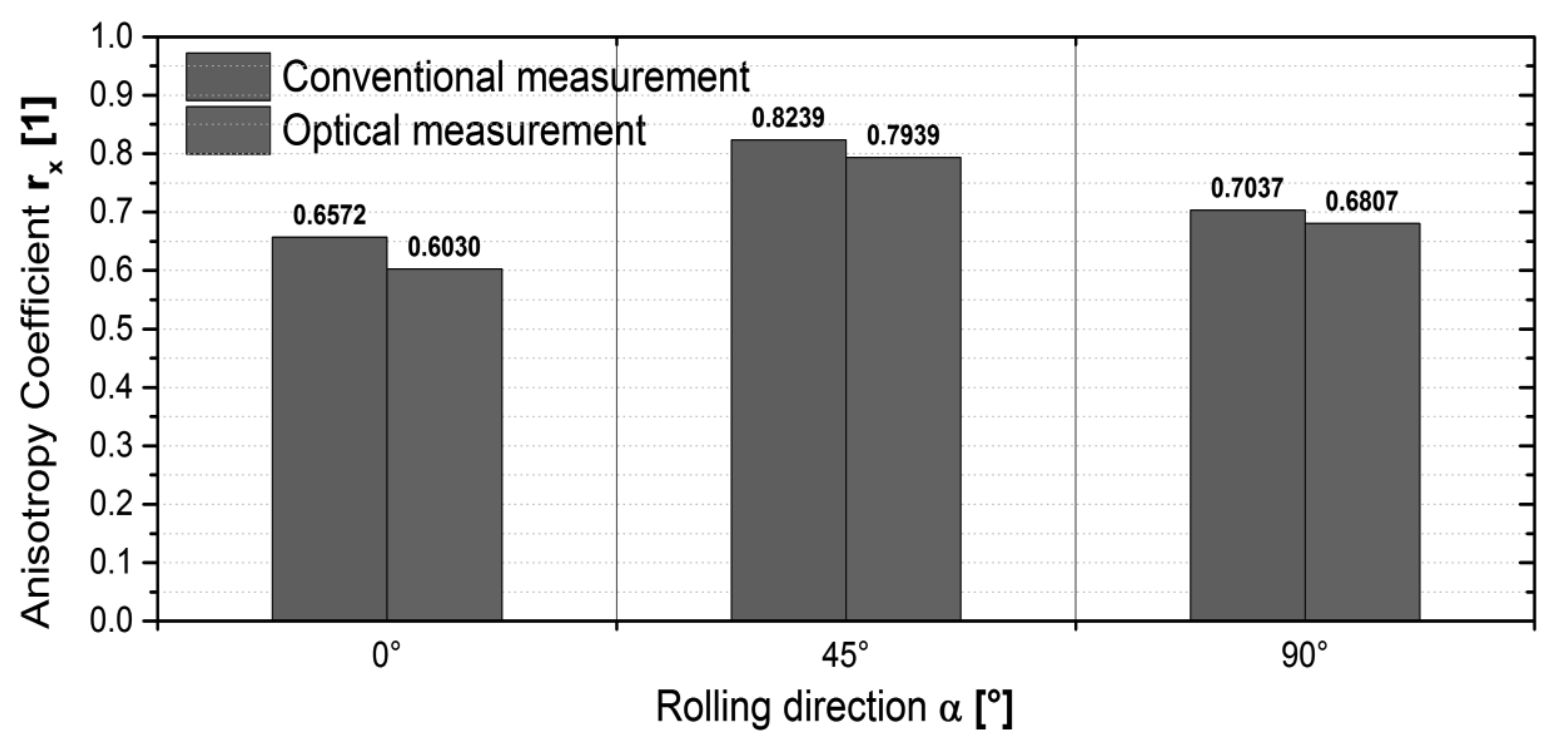

Fig. 11 Detailed comparison of the major results 
Detailed graphical comparison of the results measured both by the conventional measurement (crosses) and by the contact-less optical measurement (lines) is shown in Fig. 12. For the better clearness is there also shown the vertical line for $\varepsilon_{\mathrm{ENG}}=0,140$ - thus value that was used during the conventional measurement. Note again that such comparison right for one value on $\mathrm{X}$-axis is quite confusing due to the deformation behaviour of tested material AW 5182 (creation of so-called Lüders bands), which makes a lot of peaks and valleys on the final measured curves.

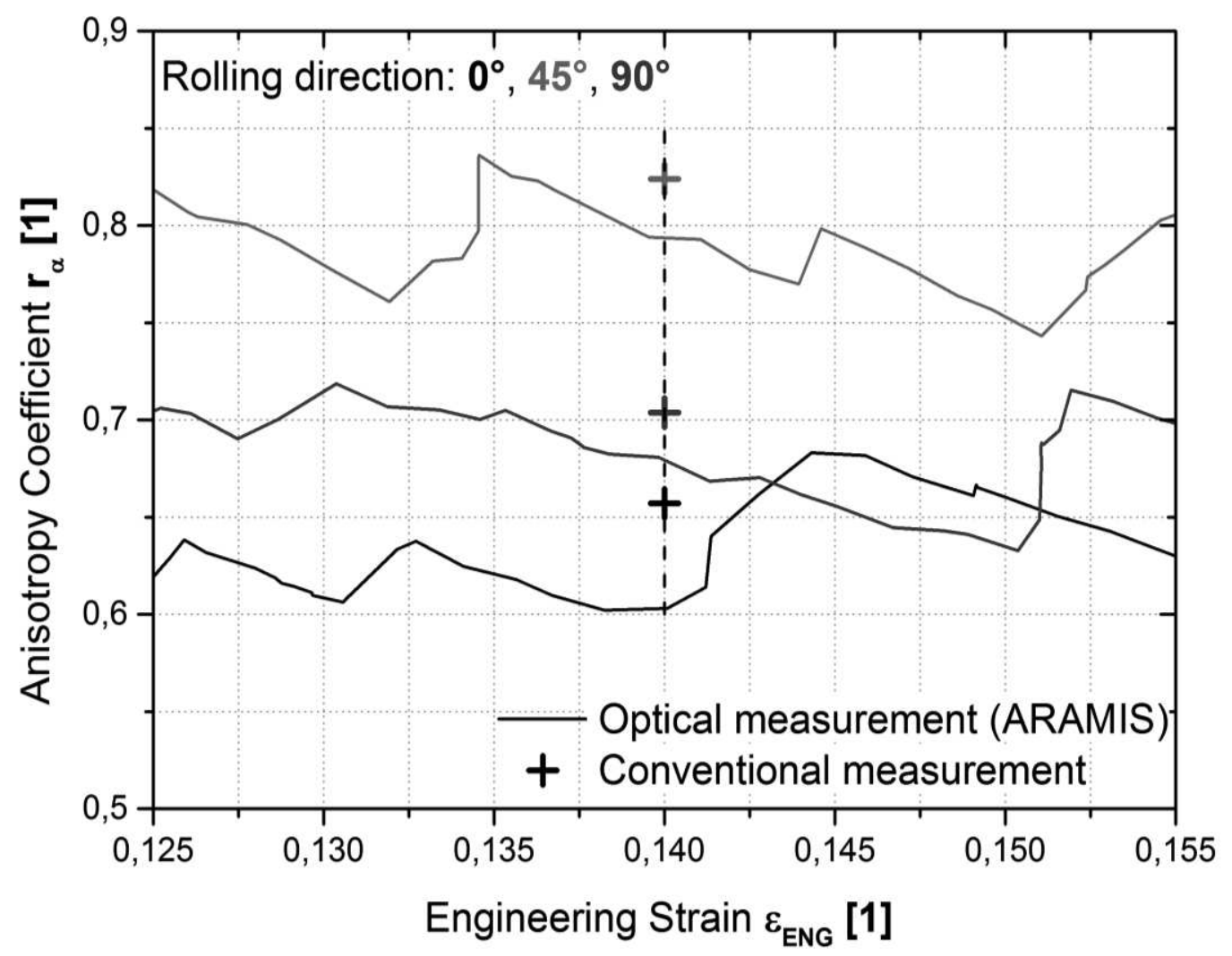

Fig. 12 Detailed comparison of the major results

\section{Conclusion}

The major aim of this paper was to perform the contactless optical measurement of anisotropy coefficient. As a testing material there was chosen the aluminium alloy AW 5182 of thickness 1,2 mm. The main reason for such selection rested in its specific deformation behavior, because this material is typical for creation of the Lüders bands.

As a major result there was not only comparison of final values measured by two different methods, but there was also effort to determine the own applicability of contact-less optical measurement in this case of a specific deformation behavior - creation of Lüders bands. In light of the results comparison, there were not observed any big differences between two used measuring methods: $8,24 \%,-3,64 \%$ and $-3,26 \%$ with respect to rolling direction and taking the conventional measurement as $100 \%$ (basic one). So, it can be stated that optical measurement of anisotropy coefficient represents quite relevant measuring technique. On the other hand, the measured curves within the whole progress of engineering strain exhibit a little strange shape - stair-like shape. It arises from the creation of Lüders bands during deformation of aluminium alloy AW 5182 and its influences is obvious already from the magnitudes of measured widths within the whole test - see Fig. 5 (right). That is why there was not performed any smoothening of measured values - such behavior is given by the material. Last but not least - such approach proved that this method can be used also for materials having anisotropy coefficient lower than 1 . The final graphical comparison is shown in Fig. 13.

Nevertheless, in this paper was measured only one value by means of conventional measurement and only one aluminium alloys of $5^{\text {th }}$ series. It should be very positive to perform other tests which will concern these factors as well as e.g. also other types of materials (deepdrawing and ultra high-strength steels, magnesium alloys, etc.). 


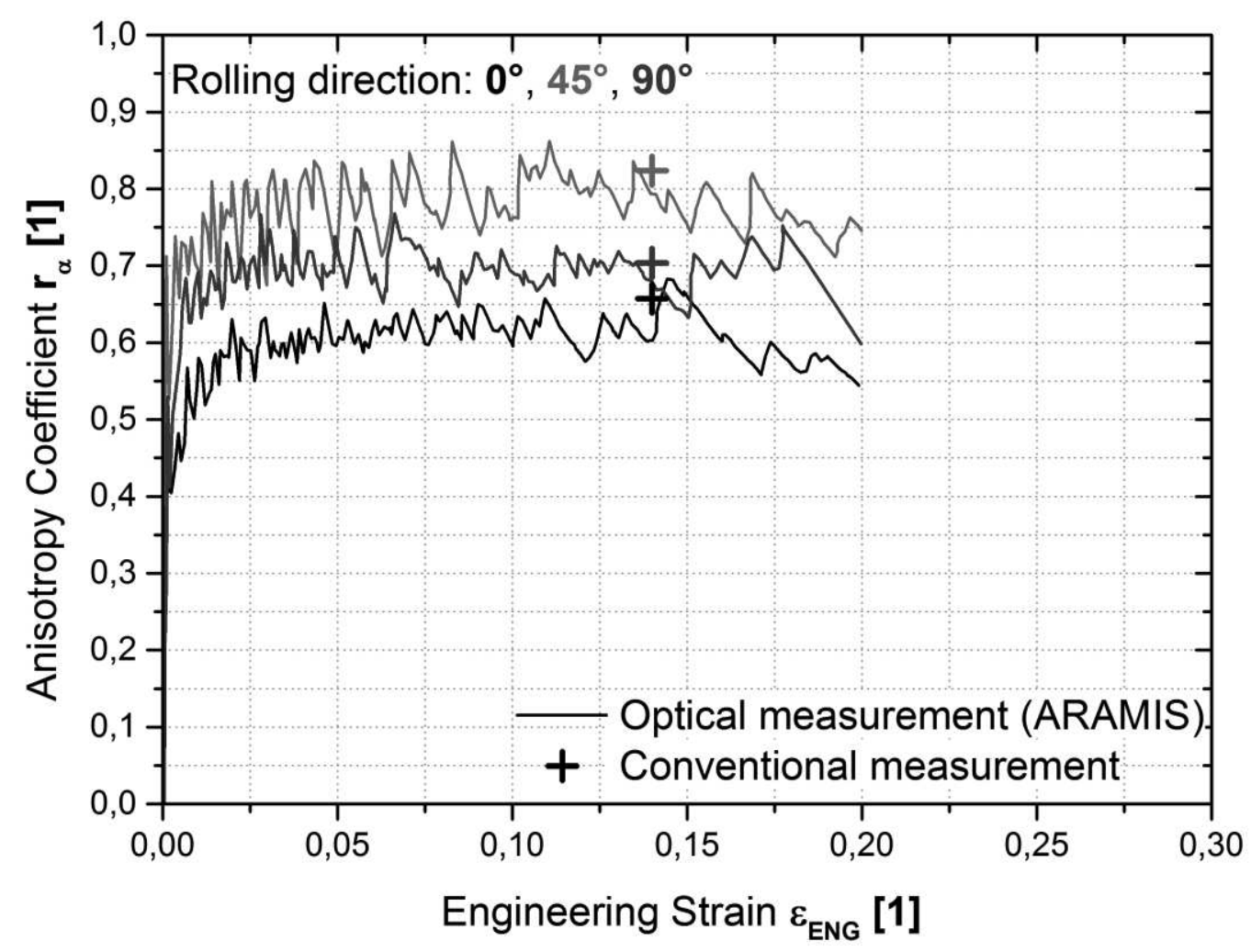

Fig. 13 Final graphical comparison of all important results

\section{References}

[1] KUHN, H., D. MEDLIN, ed. (2000). ASM HANDBOOK Volume 8 - Mechanical Testing and Evaluation. ASM International, Materials Park.

[2] DAVIES, G.(2003) Materials for Automobile Bodies. Butterworth-Heinemann, Oxford.

[3] POLMEAR, I.(2006) Ligth Alloy - From traditional Alloys to Nanocrystals. Butterworth-Heinemann, Oxford.
[4] PRUSA, F. et al. (2015) Mechanical Alloying: A Way How to Improve Properties of Aluminium Alloys. pp. 1036-1043. Manufacturing Technology, Volume 15.

[5] NESLUSAN, M. et al. (2016) Magnetic Anisotropy of Hard Milled Surfaces. pp. 1073-1078. Manufacturing Technology, Volume 16.

\subsection{2/ujep/357.2019/a/1213-2489/MT/19/4/692}

Copyright $($ 2019. Published by Manufacturing Technology. All rights reserved. 